\title{
Future of clinical leadership; the to-do list
}

\author{
Judith Tweedie, ${ }^{1,2}$ Jane Dacre ${ }^{1}$
}

${ }^{1}$ Royal College of Physicians, London, UK

${ }^{2}$ Medical Education, University College London Medical School, London, UK

\section{Correspondence to}

Dr Judith Tweedie, Royal College of Physicians, London NW1

4LE, Uk;

Judith.Tweedie@rcplondon. ac.uk

Received 21 July 2017

Accepted 16 August 2017

Published Online First

7 September 2017

\begin{abstract}
What does the future hold for clinical leadership? This article addresses the potential challenges clinical leaders will face and outlines strategies for overcoming these. The article begins by reviewing the current healthcare landscape and the role the clinicians play in shaping this landscape. The top nine priorities ('to do' list) in healthcare are summarised and the need for clinicians to find solutions to these challenges. The article concludes by describing a new style of professionalism which will be required for effective leadership in complex adaptive healthcare systems. As clinicians, we have a responsibility to improve the processes and organisations which provide care for the patients we treat, the NHS needs talented, committed and dedicated individuals to step forward and meet these demands.
\end{abstract}

\section{BACKGROUND}

As a Medical Royal College President and a National Medical Director's Clinical Fellow, we have both found ourselves in clinical leadership positions. This is something that neither of us planned or felt adequately prepared for. We are not leadership academics but are doing our jobs as leaders at different levels in the health system. This article reflects those positions as we both find ourselves leading because of a feeling that we need to resolve the issues we face as clinicians, rather than a desire to obtain a particular title or position.

\section{LIVING WITH UNCERTAINTY}

It is not possible to predict the future, and those that do so with confidence are often wrong. Who would have foretold the political events of 2016, and 2017? The vote to leave the European Union (EU), the resignation of a prime minister, the ascent of another prime minister, followed by a snap election and hung parliament?

In medicine, however, we are lucky not to be as subject to uncertainty-there are some assumptions that we can make based on recent trends. To be as prepared as possible for what comes next, we look to the past and use that to attempt to predict the future. Two things that we can be sure of are that there will still be a need for strong clinical leaders and that they will face significant challenges. We have set out the challenges below and what will need to be put in place to meet them.

To put these challenges into perspective, we first need to set out the current healthcare landscape which will form the background to our leadership perspectives.

\section{THE HEALTHCARE LANDSCAPE}

In healthcare, although the National Health Service (NHS) is still regarded as one of the best systems in the world, with evidence frequently cited to prove it $^{1}$ the system we have in the UK is struggling.

At the Royal College of Physicians (RCP), we have presented evidence that shows that, in our opinion, the NHS in 2016 was underfunded, underdoctored and overstretched. ${ }^{2}$ There is a growing body of evidence to support this view, presented by respected health service policy organisations: the Kings Fund, ${ }^{3}$ Nuffield Trust ${ }^{4}$ and the Health Foundation. ${ }^{5}$ There are frequent references to the per cent gross domestic product (GDP) spent on health compared with other health economies, with the UK's contribution to health spend falling to an estimated $6.6 \%$ of $\mathrm{GDP}^{6}$ described as a real-time reduction in health spending. This is coupled with a decrease in the funding for social care. The annual 'winter pressures' in our acute hospital trusts now extend to at least the summer months.

The population is living longer, and the average life expectancy has increased, with many people surviving, and living with chronic disease. The advances in medical science have meant that many illnesses are cured or better managed. Patient expectation has changed, because of this, with an increased assumption of effective treatment. These are all positive developments, but governments all over the world are struggling to meet the spiralling costs of health and social care.

To fix the NHS, we need a change in the way healthcare is delivered. The current strategy has evolved from policy work, like the RCP's Future Hospital Commission, and the initiatives from the NHS, such as the New Care Models. This new strategy, set out in the Five Year Forward View, emphasises the need to move to the prevention of disease, and to move care out of the hospital setting as often as possible, by increasing our focus on community and social care. Easily said ...

Clinicians need to be at the heart of this change, as who better to co-design a better system of healthcare? However, the clinicians need to be empowered and supported to do this. The future of the NHS depends on effective clinical leadership.

To be successful, our future clinical leaders will become responsible for healthcare in a different way. In addition to understanding the changing needs of the patient, they will understand the changing needs of the system and the changing needs of the clinical professional.

With the new government distracted by Brexit, health issues have been pushed to the back of the political queue for attention, but while any changes will not be centrally driven, Sustainability and transformation partnership (STPs) are still very much on the agenda, offering a focus on local clinical leadership. 


\section{LEADERSHIP}

There is an increasing literature on clinical leadership, which will be the subject of this journal. The attributes which work well in a complex system like the NHS are being articulated by academics who study the work that we clinical leaders do and the way that we do it. It sometimes feels strange to be the subject of this kind of research. The academics measure our outcomes and observe our behaviours, to see what works and what doesn't. Perhaps because of these studies, the days of the top-down command and control approaches taken in the past are ebbing away and are being replaced by an understanding of collaboration and the need for effective team working. ${ }^{7}$ There is a need for co-creation of strategy, with joint responsibility for delivery. Clinicians have not traditionally been trained in these skills. Most clinical leaders have learnt themselves, by trial and error, and are not always comfortable with the leadership roles they are now expected to assume. The 'Jane Dacre' leadership style evolved slowly and informally from a mixture of collaboration, consensus and grit, with recognition of skill and conscientiousness in others, and a strong bias towards team building.

Whichever leadership style they select, there are several areas where the clinical leaders of the future will need to focus on fixing the NHS. The implications of some of them are discussed in this article. The future trends are assumed based on experience but remember ... we cannot predict the future, and other things will arise. It is essential, however, for clinicians to get involved in all aspects of leadership of the health service. We need to be part of the solution to the issues highlighted below. We should be doing, not done to; leading, not led. This is a practical guide for the next generation on clinical leaders, highlighting some of the risks that I anticipate will be challenges to the next generation of clinical leaders.

\section{THE 'TO DO' LIST: NINE TOPICS FOR THE FUTURE CLINICAL LEADERS TO SORT OUT Workforce}

Workforce planning in the NHS is at best an inexact science, and at worst an oxymoron, and impossible to deliver. Data from the RCP Medical Workforce Unit have shown trends in the numbers of posts for consultant physicians from all specialties advertised in the UK. Last year $>40 \%$ of advertised consultant posts for physicians were not filled. ${ }^{8}$ The Trusts had the need for the positions, and the resource to dedicate to them, but there was a lack of suitable applicants. This means that we are not training enough physicians in the UK to provide the consultant workforce that the NHS needs. The gaps are found mainly in specialties where there is a significant contribution to the acute on call. How can our future clinical leaders address this problem? The first step is to gather and publish the data, so local leaders and policymakers are aware of the problem. The next is to review the requirement and to establish whether these jobs are needed or whether the roles could be done by another staff group, such as physician associates (PAs), or a reconfiguration of the service, perhaps with the community. This needs the creativity of local clinicians, who understand the nature and complexity of the work. Another possibility is to make the general medical and acute care components of this work more attractive, perhaps using financial inducements or family-friendly rotas.

In the end, we need more doctors! So, a crucial task for the future clinical leader is to find a way of getting more doctors. Training more is a good plan, but in the interim, looking to see how we can develop better exchange programmes with international partners, and sorting out the complexities that brings in the different government departments, following Brexit.

Once all of this is done, it will be the role of the future clinical leaders to alert the government to the risks of running a chronically underfunded service. In a recent RCP survey, 20\% of consultant physicians reported gaps in trainee rotas 'such that patient care was compromised', with a further 48\% reporting that this occurred 'often, but there was usually a workaround solution'. ${ }^{8}$ If these circumstances continue, future clinical leaders will need the respect and confidence to speak truth to power.

The solution, although it may not be achievable in the short term, would be to create a workforce with a modest oversupply of doctors, which allowed for both attrition, and more flexible working patterns.

\section{Morale}

England's junior doctor's industrial action was a low point in the history of the NHS. While a breakdown in contract negotiations sparked the industrial action, it became clear that concerns about working conditions had played a significant role in the antecedent growing discontent. The RCP report Being a Junior Doctor describes the results of a trainee doctor survey and listening event which took place during the dispute. ${ }^{9}$ This has documented the serious and pervasive impact of working pressures on the mental and physical health of junior doctors and captured the common sense of disempowerment and frustration. ${ }^{9}$ As a response, we published 'Keeping Medicine Brilliant'. ${ }^{10}$ Our trainees are our future and need to be valued, supported and motivated. Better systems are required to connect the experience of the junior doctor with the systems and processes which govern their working lives. The next generation of clinical leaders should learn from the past and must focus on the needs of the future workforce. The work led by Health Education England (HEE) (Enhancing Junior Doctors Working Lives ${ }^{11}$ ) makes a good start, but tomorrow's clinical leaders will be tasked with the difficult job of changing the culture in which these young doctors (and other healthcare professionals) work. The worrying data on attrition, with the trainee workforce feeling better valued outside the UK, will be difficult to improve without a concerted effort from the entire workforce. Recognition of the different aspirations of young doctors regarding work-life balance and where they wish to live and work must be heightened. The increase in female doctors should be welcomed and provided for with greater flexibility for those wishing to train and work part time. Who better to lead this than the very clinicians at the centre of the dispute, who have already demonstrated that they can be the future clinical leaders?

\section{Generalism and specialism}

The RCP was given its Royal Charter 500 years ago in 1518. In those days, all physicians were generalists. Since then, there has been a transformation in the diversity of medical specialties, and we are now home to 30 different specialty groups. Each specialty group is proud of its unique professional identity, and rightly so. The scientific and clinical progress made has increased the complexity of each of the specialties and raised the standard of care provided to those selected patients. The concurrent change in the patients we serve, however, has meant that we meet an increasing number of older people with coexisting illnesses of increasing complexity. There is a need for a strong combination of generalism and specialism to address these clinical problems and to keep patients safe. This has caused a problem in 
the professional identity of our physicians. For several years, we have been developing finely tuned specialist skills, but we now realise that we have allowed our generalist skills to have a lower status. This was recognised in the Future Hospital Commission report, which called for an increase in generalism in medicine. ${ }^{12}$ Redressing the balance will be a difficult task and requires sensitive clinical leadership, collaboration and consensus building. Currently, many specialists do not feel confident to take on more generalist responsibilities, and that they do not have the time to take on evermore clinical duties. They have a point!

The new plans for the Shape of Training, currently awaiting approval for implementation by HEE, and the Medical Royal Colleges and Deaneries, attempt to address the training concerns by adding more general medical training into the specialties. However, adding more generalism, without reducing training in the specialty, and keeping within the current time for training, or less, does not work without compromise from all sides. This agreement has not been reached for all medical specialties, and as there is no more resource, the situation remains unresolved, and a source of disquiet.

The clinical leaders of the future will need to develop a sensitive and understanding approach to making these changes, using compromise, and keeping the quality of patient safety and the quality of training to the fore.

\section{Innovation and research}

The UK has a reputation for research excellence and a very strong track record in biomedical science research. This is something that we are proud of and should maintain. The future of our research collaborations with Europe is unsure following the Brexit vote, and relationships need to be rebuilt with countries outside the EU. Research is difficult to maintain alongside clinical work, and several barriers were highlighted recently in the RCP's document 'Research for All'. ${ }^{13}$ Tomorrow's clinical leaders must try to enhance the links between our clinical and academic communities. One way to do this is to make clinical research more accessible to clinicians. Another way to encourage clinicians into research is to build expertise in areas of research endeavour that have been considered less worthy in the past, like national clinical audit, quality improvement (QI) research and medical education research. The clinical leaders running national and international journals could support this approach and drive up the standards of work in QI, audit and education by accepting a broader range of research and innovation in their publications, without compromising on rigorous peer review. Without this leadership, and without encouraging ordinary doctors to contribute to research in its broadest sense, the prowess of UK clinical research will be at risk. ${ }^{14}$ This argument is strengthened by the recent publication showing that clinical outcomes are better in research-active departments. ${ }^{15}$

\section{Regulation}

Don Berwick wrote a seminal paper in 2015 which explained what he called the 'three eras of medicine'. ${ }^{16}$ In era 1 , doctors were autonomous and powerful but then started to be greedy and to make mistakes. We then moved to era 2, the era of over-regulation. In this era, doctors are not to be trusted to manage themselves. Berwick believes that this is where we are now. This lack of trust from the public has resulted in the increase in the number of regulatory bodies with less professional self-regulation. The task on the 'to do' list for tomorrow's clinical educators is to reduce the burden of regulation, so that it is coordinated, and less burdensome, but not less effective.
The addition of more PA posts may help trainees to have time to access educational events, but has proved controversial in a junior doctor workforce, concerned about their own access to increasingly scarce training opportunities. An additional challenge for this new healthcare group in the UK is a lack of regulation. At the moment, a lack of professional regulation prevents PAs from prescribing and from requesting tests involving ionising radiation. This limits their contribution to safe healthcare delivery and reduces the level of support they can provide to the team. Regulation for PAs was not included in the recent Queens Speech, but the RCP and the Faculty of Physician Associates will keep pressing for it to happen. ${ }^{17}$

Regulation needs to maintain its force for good but to reduce the attendant bureaucratic overkill, and the associated increase in measurement and metrics rather than clinical duties. The next generation of medical leaders would be well advised to use their influence to support the development of legislation for new healthcare groups such as PAs, while maintaining a proportional level of regulation. This will take strong and collaborative clinical leadership.

\section{Education}

Education has changed radically in medicine. Its status has increased significantly, and the standards of education and assessment in the UK are now very high. One difficulty with the current system which is being addressed is the speed of change. It takes a long time to train a doctor, and it takes a long time to embed a curriculum and assessment system. This means that doctors are often trained in an outdated system, while working in the system we have today, and expected to be able to cope with the problems of tomorrow. The key to resolving this is to have strong education leaders, who can embed flexibility into the education systems we use. Often in clinical leadership change is designed and planned without adequate thought about the education and training required to implement and embed that change. Tomorrow's leaders should embed the education needs of the workforce into any change that is likely to be required. They must begin to work in tandem with tomorrow's education leaders.

There are opportunities to ensure this happens-the Shape of Training initiative is an opportunity to design a training programme for doctors which is flexible enough to meet the needs of tomorrow's learners and tomorrow's patients. The RCP's own Chief Registrar Programme-an initiative designed at familiarising our trainees with leadership requirements for the future-has already been shown to be successful in improving the morale and job satisfaction of trainees while at the same time improving the organisation of care provided to patients. The programme enables senior medical registrars to take up the post for 1 year during which they spend $40 \%-50 \%$ of their time in a leadership and management role. The chief registrars continue to participate in clinical work and contribute to the acute take while leading service redesign, educational and workforce transformation projects within their trust. The RCP's education department, in partnership with the Faculty of Medical Leadership and Management, has designed a bespoke leadership programme that develops the capability and confidence of the chief registrars in their new positions. This programme highlights the agility within the medical royal colleges to respond to healthcare and societal changes in advance of widespread changes to assessment, training and education. 


\section{Resource and efficiency}

The costs of the NHS are increasing year on year and are not sustainable. The recent work by Tim Briggs 'Getting it Right First Time (GIRFT), 18 and the recently published Atlas of Variation ${ }^{19}$ show that there is unacceptable variability in the way that health services are delivered. The most recent version highlights a wide variation in the access to and use of diagnostic tests for several common conditions. This variation in clinical care is unlikely to all be supported by best clinical evidence. The project founded in Canada named 'Choosing Wisely' has now been launched in the UK and has set a task for leaders to reduce unnecessary investigations, procedures and treatments. The recent RCP report Referring Wisely ${ }^{20}$ contributes to the debate by collating the views of specialties about which conditions should and should not be referred for an opinion.

Estimates place the cost of treating long-term conditions at $70 \%$ of total health and social care expenditure. ${ }^{21}$ Every clinical decision is also a financial decision. Tomorrow's clinical leaders will have a responsibility to ensure that the NHS can become financially sustainable into the future. They will need to develop a better understanding of health economics and financial management.

Although the principles of care closer to home and integration between primary and secondary care developed in the Future Hospital Programme were not intended to be a way of reducing health spend, many of the plans for the STP's result are considerable cost savings that some say are unachievable. ${ }^{22}$

This concern has been expressed by the major UK health think tanks, with the general conclusion that although increased efficiency and improving value in healthcare is necessary, and laudable, there remains a gap between the level and quality of service the NHS is able to provide, and the aspiration of a comprehensive fully funded first class high-quality NHS free at the point of delivery. This situation has been described as 'Mission Impossible' by NHS Providers, stating that the NHS is in the longest and deepest financial squeeze in NHS history, with a $1.3 \%$ increase in funding in an environment that required a $5 \%$ increase just to stay still. ${ }^{23}$ This is before including cancer, and mental health, while asking NHS Trusts to balance the books.

These unprecedented cost pressures are likely to increase over the next few years and will put significant pressure on tomorrow's leaders. All the collaboration, efficiency, transformation and other management tools together will struggle to deliver, which will require dedication and resilience from our clinical leaders.

\section{Politics}

Clinical leaders are a crucial resource in the NHS and have a responsibility to alert the government to the views of the medical professionals. They must be involved and influential in the future of the organisation. Clinical leaders need to be present throughout the NHS, from hospitals through local commissioning bodies, medical Royal Colleges and specialty societies to national organisational and regulatory agencies, and finally, into the Department of Health and government.

Top-level leaders in independent organisations must be able to influence government, but at the same time, to reflect the views and concerns of the organisation's membership. This is a difficult line to tread and takes experience. Too strident, and the leaders are not listened to by the government, but too quiet, and the membership has no evidence that their views have been heard.
Traditional education and training from medical schools to postgraduate training does not ordinarily equip doctors with the skills and knowledge to prepare for these clinical leadership roles in a political setting. Like professionals in many other fields, doctors are unaware of the complexity of public affairs and how to exert political influence successfully, leading to a lack of understanding, unrealistic expectations and inadequate capacity at many levels of medicine to act as effective advocates for the profession and patients. Many successful clinical leaders have often learnt 'on the job' over a lifetime in a series of leadership roles.

How much better would it be if we could equip our young doctors earlier in their careers with a better understanding of government and politics, influencing and diplomatic skills, and tactical nous to be effective patient and professional advocates?

The recent uncertainty caused by the political upheavals of Brexit and two general elections, with subsequent changes in political leadership, have distracted the government from the NHS. It is the role of the next generation of clinical leaders to bring the focus back, using timely and evidence-based debate.

\section{Moral dilemmas and a new professionalism}

In the last decade, clinical leaders have contributed to the structural and policy changes to the NHS. There are now a set of moral dilemmas which they will need to address. Medical science has been hugely successful in improving the quality of care, and in developing innovations. We have, however, caused a different problem for healthcare. There is a much-needed debate to be had about what health professionals can do for their patient, and what they should do for their patient. This argument is very difficult to articulate openly, without coming across diverse moral and religious belief and opinion.

The past decade in health has shown us how to improve services, but the innovations are expensive, complex and sometimes are focused on quantity rather than the quality of life. These dilemmas include treatment decisions, especially towards the end of life; funding decisions where the benefit is debated; and the safe and effective use of big data. The next generations of clinical leaders are likely to be involved in such debates.

These debates are not new, as the creation of the National Institute for Health and Care Excellence enabled decisions to be made based on evidence, and fewer cost pressures over the last 20 years had reduced interest in this area. The story has now changed with the current austerity climate. Tomorrow's leaders will be required to make very difficult decisions on prioritising clinical care.

All of the topics on the to do list require effective leadership and a new style of professionalism. This needs to be integrated with the development of clinical staff, and they should be prepared to debate the difficult questions coming up for health over the next 500 years.

Future leaders will require a broad range of skills which complement both clinical expertise and front-line knowledge of delivering care. These skills range from an ability to understand one's actions through to creating systems that work cohesively and deliver high-quality healthcare.

To achieve this, leaders of the future require a commitment to integrity, transparency and responsibility. Integrity is essential in providing equitable healthcare which manifests itself by leading with honesty, consistency and impartiality in an environment overrun with competing priorities. A commitment to transparency incorporates a willingness to listen and act on feedback, clear communication of organisational and professional 
motivations and openness to difficult and challenging conversations. In cultivating this transparency, future leaders can create an environment that is actively and continuously learning while promoting the safest and highest quality of care. A commitment to responsibility underpins the ability to act with integrity and create truly transparent and responsive environments. While external responsibilities will shift over the course of the career, the future leader remains cognisant of the core responsibility to govern their actions and behaviours, and seek evidence of their impact on others. The more senior the position, the more behaviours and actions will be mirrored throughout teams and organisations, and thus the acuter the responsibility becomes.

The pace and manner in which we work have changed, and the effective clinical leader will be defined by their rapid ability to create high functioning teams with clear, cohesive goals and values. A commitment to team working also requires a commitment to breaking down entrenched and outmoded concepts of hierarchy, creating open and transparent systems where all team members are valued and have a position of authority. Providing care for a population with increasingly complex healthcare requires collaborative working across professional and organisational boundaries and the development of new intraprofessional and interprofessional relationships. At every level, clinical leaders should be adept at negotiation, facilitation and consensus building for the profession to thrive.

For healthcare to function efficiently and effectively, future leaders should possess the skills previously outlined while maintaining overall vision, embracing uncertainty, cultivating teamwork and inspiring others.

\section{CONCLUSION}

As clinicians, we have a responsibility to improve the processes and organisations which provide care for the patients we treat. ${ }^{24}$ The NHS needs talented, committed and dedicated individuals to step forward and help meet the demands of healthcare in the 21st century. These individuals, in turn, need support from managerial colleagues, politicians, medical royal colleges and, most importantly, from their fellow clinical colleagues if they and healthcare are to flourish. The future leader cannot wait until they feel entirely prepared for the role, as that day is unlikely to come, but should commit every day to asking: How do I improve and how do I improve care for our patients?

Contributors This article in its entirety was written by JD and JT with editorial assistance from Ms Linda Cutherbertosn (head of PR and public affairs for the RCP).

Competing interests None declared.

Provenance and peer review Not commissioned; externally peer reviewed.

(C) Article author(s) (or their employer(s) unless otherwise stated in the text of the article) [year]. All rights reserved. No commercial use is permitted unless otherwise expressly granted.

\section{REFERENCES}

1 Davis K, Stremikis K, Squires D, et al. Mirror, mirror on the wall: how the performance of the US health care system compares internationally: The Commonwealth Fund, 2014. (accessed 6 Jul 2017).
2 Royal College of Physicians. Underfunded, underdoctored, overstretched: The NHS in 2016. London: RCP, 2016. https://www.rcplondon.ac.uk/guidelines-policy/ underfunded-underdoctored-overstretched-nhs-2016

3 Robertson R, Wenzel L, Thompson J, et al. Understanding NHS financial pressures: How are they affecting patient care? London: The King's Fund., 2017. https://www. kingsfund.org.uk/sites/default/files/field/field_publication_file/Understanding\% 20NHS\%20financial\%20pressures\%20-\%20full\%20report.pdf(accessed Jul 2017).

4 Gainsbury S, Dayan M. Behind the numbers: NHS finances Nuffield Trust briefing. London: The Nuffield Trust, 2016. https://www.nuffieldtrust.org.uk/resource/behindthe-numbers-nhs-finances(accessed Jul 2017).

5 Charlesworth A, Thorlby R, Roberts A, et al. Election briefing: NHS and social care funding Three unavoidable challenges. London: The Health Foundation, 2017. http:// www.health.org.uk/sites/health/files/Election\%20briefing\%20NHS\%20and\% 20social\%20care\%20funding.pdf(accessed Jul 2017).

6 Appleby J. How does NHS spending compare with health spending internationally? [Blog post]. https://www.kingsfund.org.uk/blog/2016/01/how-does-nhs-spendingcompare-health-spending-internationally(accessed Jul 2017).

7 West M, Steward K, Eckert R, et al. Developing Collective leadership for Healthcare. London: The King's Fund, 2014. https://www.kingsfund.org.uk/sites/files/kf/field/field_ publication_file/developing-collective-leadership-kingsfund-may14.pdf(accessed Jul 2017).

8 Gordon H. The consultant census: rota gaps in 2017: RCP, 2017. Commentary.

9 Royal College of Physicians. Being a junior doctor. London: RCP, 2016. www. rcplondon.ac.uk/guidelines-policy/being-junior-doctor(accessed Jul 2017).

10 Royal College of Physicians. Keeping Medicine Brilliant. London: RCP, 2016. https:// www.rcplondon.ac.uk/guidelines-policy/keeping-medicine-brilliant(accessed July 2017).

11 Health Education England. Enhancing junior doctors working lives. London: Health Education England, 2016. https://www.hee.nhs.uk/our-work/developing-ourworkforce/supporting-doctors-training/enhancing-junior-doctors-working-lives. (accessed July 2017).

12 Royal College of Physicians.. Future Hospital Commission. Future hospital: caring for medical patients. A report from the Future Hospital Commission to the Royal College of Physicians. London: RCP, 2013. https://www.rcplondon.ac.uk/projects/outputs/ future-hospital-commission(accessed Jul 2017).

13 Royal College of Physicians.. Research for all. London: RCP, 2016. https://www. rcplondon.ac.uk/projects/outputs/research-all(accessed Jul 2017).

14 Dacre J. Johnson M Research for All Benefits All. Lancet;389:p499-500.

15 Downing A, Morris EJ, Corrigan N, et al. High hospital research participation and improved colorectal cancer survival outcomes: a population-based study. Gut 2017;66:89-96.

16 Berwick DM. Era 3 for Medicine and Health Care. JAMA 2016;315:1329-30.

17 Royal College of Physicians. RCP response to queens speech. https://www.rcplondon. ac.uk/news/rcp-response-queens-speechBritish

18 Orthopaedic Association. A national review of adult elective orthopaedic services in England. London: BOA, 2015. https://www.boa.ac.uk/wp-content/uploads/2015/03/ GIRFT-National-Report-Mar15.pdf(accessed Jul 2017).

19 Public Health England and NHS England. The NHS Atlas of Variation in Healthcare. Reducing unwarranted variation to increase value and improve quality. London: Public Health England, 2015. http://fingertips.phe.org.uk/profile/atlas-of-variation. (accessed Jul 2017).

20 Royal College of Physicians. Referring Wisely. London: RCP, 2017. https://www. rcplondon.ac.uk/projects/outputs/referring-wisely(accessed Jul 2017).

21 Department of Health. Long term conditions compendium of information. $3^{\text {rd }}$ edition. London: Department of Health, 2012. of Health (20ort. https://www.gov.uk/ government/publications/long-term-conditions-compendium-of-information-thirdedition(accessed July 2017).

22 Sustainability and Transformation Plans (STPS) What do they mean for physicians? London: RCP. https://www.rcplondon.ac.uk/projects/outputs/backgroundsustainability-and-transformation-plans-stps(accessed July 2017).

23 Hopson C. Mission Impossible: The NHS can't deliver in 2017. [Blog post]. https:// nhsproviders.org/news-blogs/blogs/mission-impossible-the-nhs-cant-deliver-in201718(accessed July 2017).

24 General Medical Council (2012) Leadership and management for all doctors. London: GMC. http://www.gmc-uk.org/Leadership_and_management_for_all_doctors_FINAL. pdf_47234529.pdf(accessed July 2017). 